\title{
Feeding sodium selenite and nano-selenium stimulates growth and oxidation resistance in broilers
}

\author{
A.A. Saleh ${ }^{1 \#} \&$ T.A. Ebeid ${ }^{1,2}$ \\ ${ }^{1}$ Department of Poultry Production, Faculty of Agriculture, Kafrelsheikh University, 333516 Kafrelsheikh, Egypt \\ ${ }^{2}$ Department of Animal Production and Breeding, College of Agriculture and Veterinary Medicine, Qassim University, \\ 51452 Buraydah, Saudi Arabia
}

(Received 30 June 2018; Accepted 28 January 2019; First published online 26 March 2019)

\author{
Copyright resides with the authors in terms of the Creative Commons Attribution 4.0 South African Licence. \\ See: http://creativecommons.org/licenses/by/4.0/za \\ Condition of use: The user may copy, distribute, transmit and adapt the work, but must recognise the authors and \\ the South African Journal of Animal Science
}

\begin{abstract}
Nano-elemental selenium (nano-Se) has attracted more attention than sodium selenite (SS), owing to its low toxicity, high bioavailability, strong adsorbing ability and high catalytic efficiency. The purpose of the present study was to examine the effects of dietary supplementation with SS and nano-Se on the growth performance, digestibility, blood parameters and gene expressions related to growth and oxidation in broilers. Thirty broiler chicks at 15 days old were randomly divided into three dietary treatments, namely control (basal diet without any supplementation with selenium (Se)); SS treatment (basal diet $+1 \mathrm{mg} \mathrm{SS} / \mathrm{kg}$ diet); and nano-Se treatment (basal diet $+0.5 \mathrm{mg}$ nano-Se/kg diet). The birds were given the experimental diets from 15 to 27 days old. Bodyweight gain was enhanced in the nano-Se group, but was not influenced by SS supplementation. Breast muscle and thigh muscle weights were higher in dietary supplementation of nano-Se. Although muscle fat and Se content were significantly higher in dietary supplementation of SS and nano-Se in comparison with control, muscle thiobarbituric acid reactive substance (TBARS) and a-tocopherol concentrations were not influenced. Moreover, by feeding SS or nano-Se, glutathione peroxidase (GPX) and superoxide dismutase (SOD) mRNA expressions in muscles were higher than in the control group. Plasma total cholesterol and triglyceride concentrations were significantly lower in the nano-Se group than in the other groups, while, plasma high-density lipoprotein (HDL) cholesterol, serum aspartate aminotransferase (AST) and triiodothyronine $\left(T_{3}\right)$ were not significantly affected. However, mRNAs levels in muscle tissue, namely insulin-like growth factor-I (IGF-I), insulin receptor (IR) and glucose transporters (Glut-8) were significantly higher; while atrogin-1 was not significantly affected by dietary Se supplementation. It could be concluded that dietary SS and nano-Se might be involved in improving growth performance, muscle Se content and antioxidative properties in broilers.
\end{abstract}

Keywords: Antioxidative status, growth, digestibility, gene expressions

\#Corresponding author: ahmed.saleh1@agr.kfs.edu.eg

\section{Introduction}

Trace elements are fundamental to the maintenance of health, growth and a myriad of biochemicalphysiological functions (Scott et al., 1982). Selenium (Se) is an essential trace element that is needed for normal physiological functions such as growth and reproduction (Suraï, 2002). Selenium could be presented in inorganic, organic and nano-particles forms in animal feed. Fairweather-Tait \& Hurrell (1996) indicated that several dietary factors influence the availability of Se, including heavy metals, thiols, methionine and vitamin C. The chemical form and concentration of Se have significant roles in the rate of absorption, retention and metabolism. Wright \& Bell (1966) illustrated that the duodenum is the main part for Se absorption. Most inorganic Se is excreted in urine, while nano-Se particles are excreted in faeces (Hitchcock et al., 1978; Saleh, 2014a). The inorganic form of $\mathrm{Se}$ (sodium selenite $\left(\mathrm{Na}_{2} \mathrm{SeO}_{3}\right)(\mathrm{SS})$ ) is low in bioavailability, accelerates oxidization processes and might be toxic, especially at high levels (Suchý et al., 2014). Nanotechnology holds great promise for medication and nutrition. Currently, elemental nano-Se has gained interest owing to its low toxicity, high adsorbing ability, high bioavailability and high catalytic efficiency in 
comparison with selenite in chickens (Wang et al., 2009), sheep (Shi et al., 2011a) and goats (Shi et al., 2011b).

The antioxidant effect of Se on the stability of broiler chicken meat has been reported by various authors (Liao et al., 2012; Yang et al., 2012; Rama Rao et al., 2013). It is known that natural antioxidants have a vital role in protecting cells against reactive oxygen species (ROS) by reducing the formation of free radicals and preventing lipid peroxidation (Grashorn, 2007). Moreover, the antioxidant system has several enzymes, including superoxide dismutase (SOD, EC 1.15.1.1), glutathione peroxidase (GPx, EC 1.11.1.9), and catalase (EC, 1.11.1.6) (Suraï, 2002). Selenium is an important trace element that up-regulates a vital component of the antioxidant defence mechanism by controlling the body's glutathione pool and its major Se-dependent antioxidant enzymes (GPx and SOD) (Yoon et al., 2007; Jiang et al., 2009). These enzymes can help in reducing the concentration of hydrogen peroxide and lipid peroxides (Arthur, 2000), and enhance the immune response in numerous species (Rayman, 2004; Ebeid et al., 2013). Several studies have illustrated that the dietary Se form influences growth performance, meat quality characteristics and antioxidative properties in chickens (Wang \& Xu, 2008). However, according to the knowledge of the authors, data on oxidation resistance in muscles of broilers using nano-Se are limited. Therefore, the aim of the current study was to compare the efficiency of various forms of Se (SS and nano-Se) on growth performance, blood biochemical constituents, oxidation resistance and genes expression related to growth and oxidation in broilers.

\section{Materials and Methods}

The present experiment was conducted in accordance with the guidelines of Kagoshima and Kafrelsheikh Universities and approved by the Committee of Local Experimental Animal Care, Faculty of Agriculture, Kafrelsheikh University, Egypt (Number 4/2016 EC). All precautions were followed to decrease suffering over the experimental period. One hundred one-day-old broiler chicks were housed in an electrically heated battery brooder and provided with water and a commercial starter diet. On day 12, 30 male birds with similar bodyweight were selected and housed individually in a wire-bottomed aluminium cage $(49 \times 39 \times 59 \mathrm{~cm})$. The birds were preconditioned for three days prior to treatment. The chicks were randomly divided into three equal treatments, namely control (basal diet without any supplementation with Se); SS treatment (basal diet $+1 \mathrm{mg} \mathrm{SS} / \mathrm{kg}$ diet); and nano-Se treatment (basal diet $+0.5 \mathrm{mg}$ nano-Se $/ \mathrm{kg}$ diet). The doses of Se in the present experiment were based on high bioavailability of nano-Se in comparison with SS (Zommara et al. 2007). Selenium nano-particles were prepared according to Zommara et al. (2007) and Prokisch et al. (2008) and obtained from the National Collection of Agricultural and Industrial Microorganisms, Budapest, Hungary. The experimental diets were formulated with ground yellow corn and soybean meal (Table 1) and were supplied from 15 to 27 days old. In contrast to a commercial application, no additional Se was supplemented to the basal diet, thus providing a low Se basal diet containing only the endogenous Se in the ingredients of the feed. The basal diet contained approximately $0.25 \pm 0.002 \mathrm{mg} \mathrm{Se} / \mathrm{kg}$ diet, as measured by Inductively coupled plasma mass spectrometry (ICP-MS), according to Wolf et al. (2008). The levels of Se in the control diet and treatment diets were within the safely levels of the broilers. Feed and water were provided ad libitum. The experiment was carried out in a temperature-controlled room with a 14 hours light, 10 hours dark cycle. The room temperature was kept at $25^{\circ} \mathrm{C}$, with relative humidity between $50 \%$ and $70 \%$. Body weights were recorded every three days, and feed intake was recorded daily. At the end of the experimental period, the birds were slaughtered and then dissected to measure the breast and thigh muscle weights and abdominal fat. Blood samples were collected in heparinized test tubes, centrifuged at $6000 \times \mathrm{g}$ for 10 minutes at $4{ }^{\circ} \mathrm{C}$ to separate the plasma, and stored at $-20^{\circ} \mathrm{C}$ until analysis.

The diets and faeces were dried in an oven at $105^{\circ} \mathrm{C}$. After drying, the samples were ground and passed through a $0.5 \mathrm{~mm}$ screen to facilitate analysis of the dry matter content. The chromic oxide content was analysed according to the procedure described by Guzman-Cedillo et al. (2017). The nitrogen content was determined using the Kjeldahl method. Crude protein and Se digestibilities were analysed according to the procedure described by the AOAC (2005). The following equation was used for the calculation of nutrient digestibility:

\section{Digestibility (\%): $100-\left[100 \times\left(\right.\right.$ diet $\mathrm{Cr}_{2} \mathrm{O}_{3} /$ faeces $\left.\mathrm{Cr}_{2} \mathrm{O}_{3}\right) \times($ faeces / diet nutrient) $]$}

Blood plasma concentrations of total cholesterol (TC), triglyceride (TG), HDL-cholesterol and glucose, and aspartate aminotransferase (AST, EC 2.6.1.1) activity were measured with an automated Fuji DRYCHEM 3500 (Fuji Medical Systems, Tokyo, Japan) using commercial kits. The concentration of plasma triiodothyronine $\left(T_{3}\right)$ was measured with a commercial enzyme immunoassay kit (ELISA-T, International Reagents Corp., Kobe, Japan). The content of thiobarbituric acid reactive substance (TBARS) in the muscles and muscle total fat was measured by the method of Ohkawa et al. (1979). The concentration of 
a-tocopherol in the muscle tissue was determined with a Shimadzu HPLC model LC6A (Tokyo, Japan) with a Shim-Pack CLC-ODS column $(6.0 \times 150 \mathrm{~mm})$, according to Faustman et al. (1989).

Table 1 Composition and nutrient analysis of basal diet for broilers

\begin{tabular}{|c|c|}
\hline Ingredients,\% & Diet \\
\hline Corn & 50.19 \\
\hline Alfalfa meal & 2.64 \\
\hline Soybean meal, 46\% & 39.01 \\
\hline Corn oil & 4.40 \\
\hline L-lysine $\mathrm{HCl}$ & 0.01 \\
\hline DL-methionine & 0.18 \\
\hline Mineral $^{1}$ mix & 3.31 \\
\hline Vitamin $^{1}$ mix & 0.26 \\
\hline \multicolumn{2}{|l|}{ Calculated analysis } \\
\hline Crude protein, $\%$ & 22.60 \\
\hline Metabolisable energy, $\mathrm{KJ} / \mathrm{kg}$ & 12890.9 \\
\hline Calcium, \% & 1.10 \\
\hline Phosphorus, \% & 0.46 \\
\hline Sodium, \% & 0.26 \\
\hline Chlorine, \% & 0.25 \\
\hline
\end{tabular}

\footnotetext{
${ }^{1}$ Mineral-vitamin permix supplied per kilogram feed: Mn: $154 \mathrm{mg}, \mathrm{Zn}: 121 \mathrm{mg}, \mathrm{Fe}: 176 \mathrm{mg}$, Cu: $33 \mathrm{mg}, \mathrm{I}: 1.1 \mathrm{mg}$, vitamin A: $3784 \mathrm{mcg}$, vitamin D: $0.066 \mathrm{mcg}$, vitamin E: $110.11 \mathrm{mcg}$, vitamin $B_{12}: 12 \mathrm{mg}$, retinol: $1.37 \mathrm{mg}$, cholecalciferol: $0.13 \mathrm{mg}$, riboflavin: $6.50 \mathrm{mg}$, thiamine hydrochloride: $2.60 \mathrm{mg}$, pyridoxamine hydrochloride: $1.30 \mathrm{mg}$, cyanocobalamin: $0.03 \mathrm{mg}$, D-pantothenic acid: $10.40 \mathrm{mg}$, nicotinic acid: $26.00 \mathrm{mg}$, vitamin K3: $1.05 \mathrm{mg}$, pteroylglutamic acid: $0.52 \mathrm{mg}$, choline chloride: $0.78 \mathrm{mg}$, biotin: $0.07 \mathrm{mg}$, sucrose: $2.54 \mathrm{~g}$
}

Total RNA was extracted from the pectoralis superficial muscle using an RNeasy ${ }^{\circledR}$ fibrous tissue mini kit (Qiagen, Tokyo, Japan) according to the manufacturer's protocol. The RNA concentration and purity were determined spectrophotometrically with a photometer (BioPhotometer, Eppendorf, Hamburg, Germany) to obtain the A260 and A280 values. The A260/A280 ratios for all samples were between 1.8 and 2.0. cDNA was synthesized with $800 \mathrm{ng}$ RNA per $20 \mathrm{~mL}$ of reaction solution using the PrimeScript ${ }^{\mathbb{B}}$ RT reagent Kit (Perfect Real Time, Takara, Shiga, Japan) and the Program Temp Control System PC320 (Astec, Fukuoka, Japan) with the following conditions: reverse transcription $37{ }^{\circ} \mathrm{C}$ for $15 \mathrm{~min}$, inactivation of reverse transcriptase at $85{ }^{\circ} \mathrm{C}$ for 5 seconds, and refrigeration at $4{ }^{\circ} \mathrm{C}$ for $5 \mathrm{~min}$. Real-time PCR primers were prepared as described. Gene expression was measured via a real-time polymerase chain reaction (RealTime PCR) (Real-Time PCR) using the 7300 real time PCR system (Applied Biosystems, Foster, USA) with SYBR $^{\circledR}$ Premix Ex Taq ${ }^{\mathrm{TM}}$ (Perfect Real Time, Takara, Shiga, Japan) and specific primers for candidate genes (Table 2). The thermal cycler conditions consisted of 1 cycle at $95^{\circ} \mathrm{C}$ for 10 seconds and then 30 cycles at $95{ }^{\circ} \mathrm{C}$ for 5 seconds, and $60{ }^{\circ} \mathrm{C}$ for 30 seconds. The expression of glyceraldehyde-3-phosphate dehydrogenase (GAPDH) mRNA was used as an internal standard, and it was not significantly different among the experimental groups. The gene expression results are shown as the percentage of the control value.

The significance of differences was evaluated by an ANOVA and Tukey's multiple range test. All statistical analyses were performed using SAS version 9 (SAS, 2004). Prior to statistical analysis, the Kolmogorov-Smirnov test was used to test for normal distribution of the data. This test showed that the data reasonably followed the normal distribution. Data are reported as means \pm standard division (SD). A $P$-value $<0.05$ was considered statistically significant. 


\section{Results}

Data presented in Table 3 explain the effects of dietary supplementation with SS and nano-Se on growth performance and digestibility of crude protein and Se in broiler chickens. Body weight gain, crude protein digestibility and Se digestibility were higher when feeding nano-Se and SS $(P<0.05)$. However, feed intake was not significantly influenced. Thus, feed conversion ratio (FCR) was enhanced because of dietary Se supplementation.

Table 2 Primers used in qPCR

\begin{tabular}{lll}
\hline Gene & Forward (5'-----3') & Reverse (5'-----3') \\
\hline Atrogin-1 & CCAACAACCCAGAGACCTGT & GGAGCTTCACACGAACATGA \\
$I G F I$ & GCTGAGCTGGTTGATGCTCT & CACGTACAGAGCGTGCAGAT \\
$I R$ & CGCTGAGAATAACCCTGGTC & GCTGCCATCTGGATCATTTC \\
Glut8 & CCAAATGGGAACAACTCATCAA & GGGCAAAACCAGCAACAAA \\
GPX & TTGTAAACATCAGGGGCAAA & GGGCCAAGATCTTTCTGTAA \\
SOD & AGGGGGTCATCCACTTCC & CCCATTTGTGTTGTCTCCAA \\
GAPDH & CCTCTCTGGCAAAGTCCAAG & CATCTGCCCATTTGATGTTG
\end{tabular}

Table 3 Effects of feeding sodium selenite and nano-selenium on growth performance and digestibility in broilers

\begin{tabular}{lccc}
\hline \multirow{2}{*}{ Variable } & \multicolumn{3}{c}{ Group } \\
\cline { 2 - 4 } & Control & Sodium selenite & Nano-Se \\
\hline IBW (g) & $401.8 \pm 56$ & $402.3 \pm 54$ & $402.1 \pm 57$ \\
BWG (g/12 day) & $515^{\mathrm{b}} \pm 140$ & $514^{\mathrm{b}} \pm 135$ & $756^{\mathrm{a}} \pm 198$ \\
FI (g/12 day) & $1105 \pm 117$ & $1090 \pm 161$ & $1173 \pm 172$ \\
FCR & $2.15^{\mathrm{a}} \pm 0.58$ & $2.12^{\mathrm{ab}} \pm 0.21$ & $1.55^{\mathrm{b}} \pm 0.61$ \\
Crude protein digestibility (\%) & $59.5^{\mathrm{b}} \pm 5.5$ & $61.12^{\mathrm{ab}} \pm 1.8$ & $65.92^{\mathrm{a}} \pm 8.7$ \\
Selenium digestibility (\%) & $38.9^{\mathrm{b}} \pm 2.7$ & $46.4^{\mathrm{a}} \pm 3.5$ & $44.5^{\mathrm{ab}} \pm 8.3$ \\
\hline
\end{tabular}

IBW: initial body weight; BWG: bodyweight gain; FI: feed intake; FCR: feed conversion ratio

Means bearing different superscript letters within the same row are significantly different at $(P<0.05)$;

Values are expressed as mean \pm standard deviation of the mean; $n=7$

The results of the effects of various dietary sources of Se on organ weights and muscle chemical composition in broilers are presented in Table 4. Breast muscle and thigh muscle weights were significantly higher with the feeding of nano-Se, while, liver and heart weights were not significantly influenced by treatments. However, abdominal fat weight was significantly lower when diets were supplemented with SS and nano-Se than the control group. Muscle fat and muscle Se contents were significantly higher with supplementation with SS and nano-Se, while muscle concentration of TBARS and a-tocopherol were not affected significantly.

The influences of various dietary forms of Se on blood plasma constituents are presented in Table 5 . Plasma TC and TG were significantly lower in the nano-Se group than other treatments. However, plasma glucose, $T_{3}, \mathrm{HDL}$-cholesterol and AST were not influenced significantly.

The effects of dietary supplementation with SS or nano-Se on mRNAs expressions of gene-related growth IGF-I, IR, Glut-8 and atrogin-1 are presented in Table 6. The mRNAs expressions of IGF-I, IR and Glut-8 were significantly higher with dietary supplementation of nano-Se, while mRNA expression of atrogin-1 was not affected significantly.

With regard to the effects of dietary treatments on mRNA expressions of GPx and SOD, interestingly both gene expressions were significantly higher owing to dietary supplementation of nano-Se and SS in 
comparison with the control group (Table 6).

Table 4 Effects of feeding sodium selenite and nano-selenium on organ weights and muscle chemical composition in broilers

\begin{tabular}{|c|c|c|c|}
\hline \multirow{2}{*}{ Variable } & \multicolumn{3}{|c|}{ Group } \\
\hline & Control & Sodium selenite & Nano-Se \\
\hline Breast muscle weight (g/100 g BW) & $15.9^{b} \pm 0.9$ & $16.2^{b} \pm 1.6$ & $18.8^{\mathrm{a}} \pm 1.7$ \\
\hline Thigh muscle weight (g/100 g BW) & $16.4^{b} \pm 1.1$ & $16.4^{\mathrm{b}} \pm 0.81$ & $17.5^{\mathrm{a}} \pm 0.92$ \\
\hline Liver weight (g/100 g BW) & $2.22 \pm 0.24$ & $2.75 \pm 0.26$ & $2.14 \pm 0.47$ \\
\hline Heart weight (g/100 g BW) & $0.55 \pm 0.07$ & $0.47 \pm 0.08$ & $0.53 \pm 0.07$ \\
\hline Abdominal fat weight (g/100 g BW) & $0.46^{a} \pm 0.2$ & $0.38^{\mathrm{ab}} \pm 0.3$ & $0.28^{\mathbf{b}} \pm 0.2$ \\
\hline Muscle fat (g/100 g muscle) & $1.2^{\mathrm{b}} \pm 0.6$ & $2.02^{\mathrm{a}} \pm 0.9$ & $2.0^{a} \pm 0.7$ \\
\hline Muscle TBARS (nmol MDA/g) & $9.5 \pm 0.9$ & $8.9 \pm 0.4$ & $7.77 \pm 01.2$ \\
\hline Muscle $\alpha$-tocopherol (mg/100 g muscle) & $0.42 \pm 0.1$ & $0.35 \pm 0.02$ & $0.36 \pm 0.02$ \\
\hline Muscle selenium content (mg/100 g muscle) & $3.27^{\mathbf{b}} \pm 0.4$ & $4.9^{\mathrm{a}} \pm 0.5$ & $3.97^{\mathrm{ab}} \pm 0.3$ \\
\hline
\end{tabular}

BW: body weight; TBARS: thiobarbituric acid reactive substance; MDA: malondialdehyde Means bearing different superscript letters within the same row are significantly different at $(P<0.05)$ Values are expressed as mean \pm standard deviation of the mean; $n=7$

Table 5 Effects of feeding sodium selenite and nano-selenium on plasma parameters in broilers

\begin{tabular}{lccc}
\hline \multirow{2}{*}{ Variable } & \multicolumn{3}{c}{ Group } \\
\cline { 2 - 4 } & Control & Sodium selenite & Nano-Se \\
\hline Glucose $(\mathrm{mg} / \mathrm{dL})$ & $281 \pm 57$ & $267 \pm 24$ & $270 \pm 56$ \\
$T_{3}(\mathrm{nmol} / \mathrm{L})$ & $5.3 \pm 0.3$ & $5.6 \pm 0.5$ & $6.58 \pm 0.6$ \\
TC $(\mathrm{mg} / \mathrm{dL})$ & $133^{\mathrm{a}} \pm 13$ & $114^{\mathrm{b}} \pm 8$ & $102^{\mathrm{b}} \pm 28$ \\
HDL-C (mg/dL) & $94 \pm 31$ & $111 \pm 20$ & $91 \pm 22$ \\
TG (mg/dL) & $35^{\mathrm{a}} \pm 11$ & $31^{\mathrm{a}} \pm 3$ & $25^{\mathrm{b}} \pm 6$ \\
AST (I/U) & $241 \pm 64$ & $261 \pm 48$ & $268 \pm 51$ \\
& & & \\
\hline
\end{tabular}

$\mathrm{T}_{3}$ : triiodothyronine; TC: total cholesterol; HDL-C: high density lipoprotein cholesterol; TG: triglycerides; AST: aspartate amino transferase

Means bearing different superscript letters within the same row are significantly different at $(P<0.05)$;

Values are expressed as mean \pm standard deviation of the mean; $n=7$

\section{Discussion}

The main goal of the present study was to study how growth performance could be improved by feeding broilers on SS and nano-Se. Bodyweight gain (BWG), muscle weight (breast and thigh), and crude protein digestibility were improved because of dietary nano-Se. However, Se digestibility was improved significantly by feeding both Se sources in broilers (Tables 3 and 4). However, FCR and abdominal fat weight were lower in the SS and nano-Se groups $(P<0.05)$. These findings are in accord with previous studies (Dlouha et al., 2008; Heindl et al., 2010; Zhou \& Wang, 2011). Zhou \&Wang (2011) indicated that final body weight, body weight gain (BWG) and FCR were enhanced significantly in nano-Se groups in comparison with the control group. Similarly, Dlouha et al. (2008) found that dietary supplementation of $0.3 \mathrm{mg} / \mathrm{kg}$ Se from SS or Se-Chlorella improved BWG, muscle weight and FCR. The improved performance because of Se supplementation might be attributed to its involvement in regulating several enzymatic systems that interfere in energetic metabolism, and synthesising prostaglandins and metabolism of the essential fatty acid apurinic and a pyrimidinic base (Sara \& Odagiu, 2008; Ebeid, 2012; Saleh, 2014b). Moreover, natural antioxidants 
could protect intestinal mucosa against oxidative damage and pathogens (Kermauner \& Laurenčič, 2008). Furthermore, Se intake appears to confer additional health benefits on the immune system and reduce inflammation (Suraï, 2002; Ebeid et al., 2013; Jianhua et al., 2000). Apparently, dietary supplementation of SS or nano-Se may have contributed to the improved performance of broilers.

Table 6 Effects of feeding sodium selenite and nano-selenium on relative expression of Insulin-like growth factor I insulin receptor, glucose transporters, atrogin-1, glutathione peroxidase and superoxide dismutase genes in the muscles of broiler chickens

\begin{tabular}{lccc}
\hline \multirow{2}{*}{ Variable } & \multicolumn{3}{c}{ Group } \\
\cline { 2 - 4 } & Control & Sodium selenite & Nano-Se \\
\hline IGF-I & $100^{\mathrm{b}} \pm 20$ & $105^{\mathrm{b}} \pm 21$ & $256^{\mathrm{a}} \pm 31$ \\
Insulin receptor & $100^{\mathrm{b}} \pm 21$ & $95^{\mathrm{b}} \pm 11$ & $201^{\mathrm{a}} \pm 6$ \\
Glut 8 & $100^{\mathrm{b}} \pm 16$ & $194^{\mathrm{a}} \pm 22$ & $211^{\mathrm{a}} \pm 13$ \\
Atrogin-1 & $100 \pm 15$ & $95 \pm 16$ & $88 \pm 17$ \\
GPx & $100^{\mathrm{b}} \pm 22$ & $197^{\mathrm{ab}} \pm 21$ & $287^{\mathrm{a}} \pm 32$ \\
SOD & $100^{\mathrm{b}} \pm 18$ & $235^{\mathrm{a}} \pm 34$ & $244^{\mathrm{a}} \pm 28$ \\
\hline
\end{tabular}

IGF-I: Insulin-like growth factor I; Glut8: glucose transporters; GPx: glutathione peroxidise; SOD: superoxide dismutase; The GAPDH gene was used as an internal reference for normalization The results are expressed as ratios relative to the expression of genes in the control group, whose expression levels were equal to $100 \%$, and reflect the means \pm SD for six birds Means within rows carrying different superscript letters are significantly different from control $(P<0.05)$

The results of the present study illustrated that plasma $T_{3}$ was numerically higher with dietary Se supplementation (Table 5). These results correspond with those of Jianhua et al. (2000), who documented that dietary Se supplementation significantly increased serum $\mathrm{T}_{3}$ level and improved the growth performance in broiler chickens. $T_{3}$ is a main hormone that regulates animal growth via organizing the protein anabolism and energy metabolism (Preter, 2000). In this context, Se has been involved in somatic growth regulation, influencing $T_{3}$ and the growth hormone-IGF axis (Moreno-Reyes et al., 2001). Interestingly, the results of this study clearly showed that dietary nano-Se supplementation had a positive effect on mRNAs of IGF-I and insulin receptor (Table 6). These results agree with those of others who concluded that Se influences IGF-I receptor expression significantly and regulates apoptosis (Ren et al., 2016). Furthermore, IGF-I is an anabolic hormone that plays an essential role in the maintenance of muscle mass and integrity, prohibiting apoptosis and protecting against oxidative stress (Arvat et al., 2000). Taken together, the findings of the current study provide evidence that dietary SS and nano-Se enhanced serum $T_{3}$ concentration and participated in modulating mRNA expression of IGF-I and insulin receptor, which consequently enhanced the growth performance in broilers.

Adequate and natural provision of important nutrients in a fitting and available form can be achieved by consumption of 'functional organic food'. This mostly means food of poultry productions (meat or eggs) when the poultry are kept on a specially adapted diet enriched with substances whose levels in standard food are insufficient. These modern 'functional organic foods' also include Se organic eggs and meats. These eggs contain super-standard levels of Se in the form of the essential amino acid Se-methionine or nano form. The Se level in a standard egg is $11 \mu \mathrm{g}$, while a Se-enriched egg contains $32.6 \mu \mathrm{g}$ of Se. The consumption of two Se-enriched organic eggs a day would cover over $70 \%$ of the Se daily dose recommended to human beings (Suchý et al., 2014). The results of the present experiment revealed that the muscle Se content was improved significantly by supplementing the diets with SS and nano-Se (Table 4). Similarly, several studies reported an enhancement in muscle Se concentration because of dietary Se supplementation (Wang \& Xu, 2008; Cai et al., 2012). An explanation for this result might be that the modest nano-Se supplementation could easily saturate selenoenzymes, and consequently markedly elevate Se concentrations in tissues (Cai et al., 2012).

One of the major results in this study was that the addition of SS or nano-Se to the diets of broiler chickens appeared to enhance the mRNA expression of GPx and SOD in muscles (Table 6). Similarly, Yuan et al. (2012) elucidated that dietary organic Se significantly elevated liver GPx mRNA level in broiler 
breeders. Zhang et al. (2008) explained that nano-Se appeared to be an excellent bioavailability because of its high catalytic efficacy, strong adsorbing ability and low toxicity. As shown in Table 4, using muscle TBARS as an index of lipid oxidation, it could be observed that dietary treatments reduced TBARS values in skeletal muscles $(P<0.05)$. These results coincide with those of previous studies, which indicated that Se plays a vital role in the body's antioxidant defence system via activating GPx and minimizing lipid peroxidation (Ebeid et al., 2013). Therefore, the present study suggests that the addition of Se via the basal diet in the form of SS or nano-Se raised muscle Se concentration and was involved in modulating the mRNA expression of GPx and SOD, which led to a minimization of lipid peroxidation (TBARS concentration) in muscles. The meat quality is thought to be affected by antioxidants such as vitamin $E$ and Se-dependent enzymes, including GPx (Ahn et al., 1998; Saleh et al., 2018). Broiler meat producers previously depended on vitamin $\mathrm{E}$ to reduce these problems, but it is now known that active utilization of vitamin $\mathrm{E}$ in the broiler body is dependent on Se-based antioxidant enzymes, and enough Se intakes is required to ensure the good use of this costly vitamin. Previous experiments with layers and broilers showed that feeding organic Se could improve levels in broiler muscle tissues and eggs (Suchý et al., 2014) and reduce the negative effect of drip loss in broiler meat (Deniz et al., 2005).

With regard to plasma biochemical parameters, Table 5 shows that plasma concentrations of total cholesterol and triglycerides were significantly lower, while plasma HDL-cholesterol and glucose were not influenced significantly by dietary nano-Se. These results might be attributed to lipolysis, which was elevated y Se intake (Oppenheimer et al., 1991). Otherwise, Se-nano particle supplementation increases the levels of 15-deoxy- $\Delta$-12, 14-prostaglandin J2 (Touyz \& Schiffrin, 2006; Vunta et al., 2007), a known peroxisome proliferator-activated receptor- $\gamma$ ligand. Activation of peroxisome proliferator-activated receptor- $\gamma$ can decrease the level of sterol regulatory element-binding protein-2, leading to depression of the cholesterol synthesis (Klopotek et al., 2006).

\section{Conclusion}

It could be assumed that dietary SS and Nano-Se is involved in improving growth performance, muscle Se content and antioxidative properties in broilers. However, supplemented Se in the nano-particle form is more effective than in the inorganic form.

\section{Ethics approval and consent to participate}

All animal protocols were approved by the Institutional Animal Care and Use Committee of Department of Biochemical Science and Technology, Faculty of Agriculture, Kagoshima University, Japan, and the Faculty of Agriculture, Kafrelsheikh University.

\section{Acknowledgements}

The author is grateful to Kagoshima Chicken Foods Co., Ltd. (Kagoshima, Japan) and all members of the department of Biochemical Science and Technology, Faculty of Agriculture, Kagoshima University, for providing technical and scientific assistance

\section{Author contributions}

AAS was responsible for conceptualization, data curation, formal analysis, investigation, methodology, project administration, software, supervision, validation, visualization, writing theoriginal draft, review andediting with the help of all members of the department of Biochemical Science and Technology, Faculty of Agriculture, Kagoshima University. TAE was responsible for writing theoriginal draft, reviewingandediting.

\section{Competing interests}

The authors declare that they have no competing interests.

\section{References}

Ahn, C.N., Chae, H.S., Kim, D.W., Yoo, Y.M., Kim, Y.K. \& Rhee, Y.C., 1998. Effects of full fat flax seed, $\alpha$-tocopherol, ascorbic acid and selenium on the storage of broiler meats. Livest. Sci. 40, 96-102.

AOAC., 2005. International official methods of analysis.200. 18th edition. Current through revision 2 (online). AOAC International, Gaithersburg, MD.

Arthur, J.R., 2000. The glutathione peroxidases. Cell. Mol. Life Sci. J. 57, 1825-1835.

Arvat, E., Broglio, F. \& Ghigo, E., 2000. Insulin-like growth factor I: Implications in aging. Drugs Aging 16, 29-40.

Cai, S.J., Wu, C.X., Gong, L.M., Song, T., Wu, H. \& Zhang, L.Y., 2012. Effects of nano-selenium on performance, meat quality, immune function, oxidation resistance, and tissue selenium content in broilers. Poult. Sci. 91, 2532-2539.

Deniz, G., Genzen, S.S. \& Turkmen, I.I., 2005. Effects of two supplemental dietary selenium sources (mineral and organic) on broiler performance and drip-loss. Rev. Med. Vet. 156, 423-426.

Dlouha, G., Sevcikova, S., Dokoupilova, A., Zita, L., Heindl, J. \& Skrivan, M., 2008. Effect of dietary selenium sources on growth performance, breast muscle selenium, glutathione peroxidase activity and oxidative stability in broilers. Czech J. Anim. Sci. 53, 265-269. 
Ebeid, T.A., 2012. Vitamin E and organic selenium enhances the antioxidative status and quality of chicken cockerel semen under high ambient temperature. Br. Poult. Sci. 53, 708-714.

Ebeid, T.A., Zeweil, H.S., Basyony, M.M., Dosoky, W.M. \& Badry, H., 2013. Fortification of rabbit diets with vitamin E or selenium affects growth performance, lipid peroxidation, oxidative status and immune response in growing rabbits. Livest. Sci. 155, 323-331.

Fairweather-Tait, S. \& Hurrell, R.F., 1996. Bioavailability of minerals and trace elements. Nutr. Res.Rev. 9, 295-324.

Faustman, C., Cassens, R. \& Schaefer, D., 1989. Improvement of pigment and lipid stability in Holstein steer beef by dietary supplementation with vitamin E. J. Food Sci. 45, 858-862.

Grashorn, M.A., 2007. Functionality of poultry meat. J. Appl. Poult. Res. 16, 99-106.

Guzman-Cedillo, A.E., Corona, L., Castrejon-Pineda, F., Rosiles-Martínez, R. \& Gonzalez-Ronquillo, M., 2017. Evaluation of chromium oxide and titanium dioxide as inert markers for calculating apparent digestibility in sheep. J. Appl. Anim. Res. 45, 275-279.

Heindl, J., Ledvinka, Z., Englmaierova, M., Zita, L. \& Tumova, E., 2010. The effect of dietary selenium sources and levels on performance, selenium content in muscle and glutathione peroxidase activity in broiler chickens. Czech $\mathrm{J}$. Anim. Sci. 55, 572-578.

Hitchcock, J.P., Miller, E.R., Keahey, K.K. \& Ullrey, D.E. 1978. Effects of arsanillic acid and vitamin upon utilization of natural supplemental selenium by swine. J. Anim. Sci. 46, 425-435.

Jiang, Z.Y., Lin, Y.C., Zhou, G.L., Luo, L.H., Jiang, S.Q. \& Chen, F., 2009. Effects of dietary selenomethionine supplementation on growth performance, meat quality and antioxidant property in yellow broilers. J. Agric. Food Chem. 57, 9769-9772.

Jianhua, H., Ohtsuka, A. \& Hayashi, K., 2000. Selenium influences growth via thyroid hormone status in broiler chickens. Br. J. Nutr. 84, 727-732.

Kermauner, A. \& Laurenčič, A., 2008. Supplementation of rabbit diet with chestnut wood extract: Effect on in vitro gas production from two sources of protein. In: Proceedings of 9th World Rabbit Congress, Verona, 1 0-13 June. pp. 689-693.

Klopotek, A., Hirche, F. \& Eder, K., 2006. PPAR gamma ligand troglitazone lowers cholesterol synthesis in HepG2 and Caco-2 cells via a reduced concentration of nuclear SREBP-2. Exp. Biol. Med. 231, 1365-1372.

Liao, X., Lu, L., Li, S., Liu, S., Zhang, L., Wang, G., Li, A. \& Luo, X., 2012. Effects of selenium source and level on growth performance, tissue selenium concentrations, antioxidation, and immune functions of heat-stressed broilers. Biol. Trace Elem. Res., 150, 158-165.

Moreno-Reyes, R., Egrise, D., Ne`Ve, J., Pasteels, J.L. \& Schoutens, A., 2001. Selenium deficiency-induced growth retardation is associated with an impaired bone metabolism and osteopenia. J. Bone Miner. Res. 16, 1556-1563.

Ohkawa, H., Ohishi, N. \& Yagi, K., 1979. Assay for lipid peroxides in animal tissues by thiobarbituric acid reaction. Anal. Biochem. 95, 351-358.

Oppenheimer, J.H., Schwartz, H.L. \& Thompson, M.P., 1991. Functional relationship of thyroid hormone-induced lipogenesis, lipolysis, and thermogenesis in the rat. J. Clin. Invest. 87, 125-132.

Preter, F.S., 2000. Organic selenium: Benefits to animal and humans, a biochemist's view. In: Proceedings of Alltech's 16th Symposium. Nottingham University Press, Nottingham. pp. 205-213.

Prokisch, J., Széles, É., Kovács, B., Daróczy, L. \& Zommara, M., 2008. Formation of metal selenium nanospheres in bacteria: Is it a possible detoxification mechanism? Vii. Alps-Adria Scientific Workshop, Cereal Research Communications, volume 36, suppl. Stara Lesna, Slovakia.

Rama Rao, S.V., Prakash, B., Raju, M.V.L.N., Panda, A.K., Poonam, S. \& Murthy, O.K., 2013. Effect of supplementing organic selenium on performance, carcass traits, oxidative parameters and immune responses in commercial broiler chickens. Asian-Austral. J. Anim. Sci. 26, 247-252.

Rayman, M.P., 2004. The use of high-selenium yeast to raise selenium status: How does it measure up? Br. J. Nutr. 92, 557-573.

Ren, G., Ali, T., Chen, W., Han, D., Zhang, L., Gu, X., Zhang, S., Ding, L., Fanning, S. \& Han, B., 2016. The role of selenium in insulin-like growth factor 1receptor (IGF-IR) expression and regulation of apoptosis in mouse osteoblasts. Chemosphere 144, 2158-2164.

Saleh, A.A., 2014a. Effect of dietary mixture of Aspergillus probiotic and selenium nano-particles on growth, nutrient digestibilities, selected blood parameters and muscle fatty acid profile in broiler chickens. Anim. Sci. Pap. Rep.32, 65-79.

Saleh, A.A., 2014b. Nigella seed oil as alternative to avilamycin antibiotic in broiler chicken diets. S. Afr. J. Anim. Sci. 44, 254-261.

Saleh, A.A., Ebeid, T.A. \& Abudabos, A.M., 2018. Effect of dietary phytogenics (herbal mixture) supplementation on growth performance, nutrient utilization, antioxidative properties, and immune response in broilers. Environ. Sci. Pollut. Res. 25, 27031-27038.

Sara, A. \& Odagiu, A., 2008. Probiotics and minerals availability in organic animal farming. Pro-Environment 2, 34-38.

Scott, M.L., Nesheim, M.C. \& Young, R.J., 1982. Nutrition of the Chicken. 3rd edition. M.L. Scott \& Associates, Ithaca, NY.

Shi, L.G., Xun, W.J., Yue, W.B., Zhang, C.X., Ren, Y.S., Liu, Q., Wang, Q. \& Shi, L., 2011a. Effect of elemental nanoselenium on feed digestibility, rumen fermentation, and purine derivatives in sheep. Anim. Feed Sci. Technol. 163, 136-142.

Shi, L.G., Xun, W.J., Yue, W.B., Zhang, C.X., Ren, Y.S., Shi, L., Wang, Q., Yang, R.J. \& Lei, F.L., 2011b. Effect of sodium selenite, Se-yeast and nano-elemental selenium on growth performance Se concentration and antioxidant status in growing male goats. Small Rumin. Res. 96, 49-52. 
Suchý, P., Straková, E. \& Herzig, I., 2014. Selenium in poultry nutrition: A review. Czech J. Anim. Sci. 59, $495-503$.

Suraï, P.F., 2002. Selenium in poultry nutrition 2. Reproduction, egg and meat quality and practical applications. Wrld's Poult. Sci. J. 58, 431-450.

Touyz, R.M. \& Schiffrin, E.L., 2006. Peroxisome proliferator-activated receptors in vascular biology-molecular mechanisms and clinical implications. Vascul. Pharmacol. 45, 19-28.

Vunta, H., Davis, F., Palempalli, U.D., Bhat, D., Arner, R.J. \& Thompson, J.T., 2007. The anti-inflammatory effects of selenium are mediated through 15-deoxy-Delta12, 14-prostaglandin J2 in macrophages. J. Biol. Chem. 282, 17964-17973.

Wang, R.R., Pan, X.J. \& Peng, Z.Q., 2009. Effects of heat exposure on muscle oxidation and protein functionalities of pectoralis majors in broiler. Poult. Sci. 88, 1078-1084.

Wang, Y.B. \& Xu, B.H., 2008. Effect of different selenium source (sodium selenite and selenium yeast) on broiler chickens. Anim. Feed Sci. Technol. 144, 306-314.

Wolf, R.E., Morman, S.A., Morrison, J.M. \& Lamothe, P.J., 2008. Simultaneous speciation of arsenic, selenium, and chromium by HPLC-ICP-MS: U.S. Geological Survey Open-File Report 2008-1334, 27 p.

Wright, P.L. \& Bell, M.C., 1966. Comparative metabolism of selenium and tellurium in sheep and swine. Am. J. Physiol. 211, 6-10.

Yang, Y.R., Meng, F.C., Wang, P., Jiang, Y.B., Yin, Q.Q., Chang, J., Zuo, R.Y., Zheng, Q.H. \& Liu, J.X., 2012. Effect of organic and inorganic selenium supplementation on growth performance, meat quality and antioxidant property of broilers. Afr. J. Biotechnol. 11, 3031-3036.

Yoon, I., Werner, T.M. \& Butler, J.M., 2007. Effect of source and concentration of selenium on growth performance and selenium retention in broiler chickens. Poult. Sci. 86, 727-730.

Yuan, D., Zhan, X.A. \& Wang, Y.X., 2012. Effect of selenium sources on the expression of cellular glutathione peroxidase and cytoplasmic thioredoxin reductase in the liver and kidney of broiler breeders and their offspring. Poult. Sci. 91, 936-942.

Zhang, J., Wang, X. \& Xu, T., 2008. Elemental selenium at nano size (Nano-Se) as a potential chemopreventive agent with reduced risk of selenium toxicity: Comparison with Se-methyl selenocysteine in mice. Toxicol. Sci. 101, 22-31.

Zhou, X. \& Wang, Y., 2011. Influence of dietary nano elemental selenium on growth performance, tissue selenium distribution, meat quality, and glutathione peroxidase activity in Guangxi Yellow chicken. Poult. Sci. 90, 680-686.

Zommara, M.A., 2007. Production of organic selenium enriched yoghurt. J. Agri. Res. Kafrelsheikh Univ. 31, 820-839. 